\title{
Negación de derechos, negación de justicia: los Embera Katío
}

\author{
Denial of Rights, Denial of Justice: The Embera Katío
}

\author{
Jairo Alfonso Rebolledo $\operatorname{Vargas}^{1} \bowtie$ \\ ${ }^{\top}$ Magíster en Derechos Humanos y Derecho Internacional de los Conflictos Armados (trámite de grado). \\ Especialista en Control Fiscal, Universidad Externado de Colombia. Economista, Universidad Cooperativa \\ de Colombia, sede Bogotá. Escuela Superior de Guerra.
}

Correo electrónico: revolledova@hotmail.com

Recibido: 5 de noviembre del 2017 Aprobado: 8 de enero del 2018 Disponible en línea: 1 de abril del 2018

Cómo citar este artículo: Jairo Alfonso Rebolledo Vargas. Negación de derechos, negación de justicia: Ios embera katío. DIxI 27. Abril 2018. doi: https://doi.org/10.16925/di.v20i27.2397

\section{Resumen}

Objetivo: este artículo expone la situación de desplazamiento a la que se vio abocado el pueblo embera katío como consecuencia de la construcción de la hidroeléctrica de Urrá ( (Alto Sinú-Córdoba), privando a este grupo minoritario de su patrimonio territorial y cultural, y provocando su inminente desaparición como comunidad.

Metodología: el documento muestra cómo la corrupción política y de la justicia -a través de sus cuestionados pronunciamientos- hizo que la comunidad embera katío fuera "expulsada" de sus territorios ancestrales y reubicada en zona urbana del municipio, donde no podían realizar sus labores agrícolas, educativas, religiosas, de pesca y navegación, etc., con lo cual sus miembros se vieron sometidos a un proceso de adaptabilidad al nuevo sistema de vida hasta "desaparecer" como grupo étnico.

Resultados: a pesar de existir una legislación nacional e internacional que protege los derechos de las comunidades indígenas y de las minorías, en este caso no hubo aplicación efectiva de la ley, de modo que cuando la Corte Constitucional intervino, se enfrentó ante hechos cumplidos.

Conclusión: el no acatamiento oportuno por parte de las autoridades administradoras de justicia de los mandatos de la Constitución Nacional y los tratados internacionales derivó en una situación de desalojo, desplazamiento y posterior desaparición por aculturación de la comunidad embera katío del Alto Sinú.

Palabras clave: derechos indígenas fundamentales, consulta previa, corrupción política, indígenas embera katío, negación de justicia, represa Urrá I. 


\title{
Denial of Rights, Denial of Justice: The Embera Katío
}

\author{
Abstract \\ Aim: This article explains the situation of displacement to which the Embera Katío people were forced \\ as a result of the construction of the Urrá I hydroelectric power plant (Alto Sinú-Córdoba), depriving \\ this minority group of its territorial and cultural heritage and causing its imminent disappearance as a \\ community.
}

Methods: The document shows how political and judicial corruption-through its questioned decisions-caused the Embera Katío community to be "expelled" from their ancestral territories and relocated in the urban area of the municipality, where they could not carry out their agricultural, educational, religious, fishing and navigation, etc. activities. Therefore, its members were subjected to a process of adaptability to a new life system until "disappearing" as an ethnic group.

Results: Despite the existence of national and international legislation that protects the rights of indigenous communities and minorities, there was no effective application of the law in this case so that, when the Constitutional Court intervened, it faced accomplished facts.

Conclusion: The judicial authorities' failure to timely obey the orders of the National Constitution and international treaties led to a situation of eviction, displacement and subsequent disappearance by acculturation of the Embera Katío community from Alto Sinú.

Keywords: fundamental indigenous rights, prior consultation, political corruption, Embera Katío natives, denial of justice, Urrá I dam.

\section{Negação de direitos, negação de justiça: os Emberá Katío}

\section{Resumo}

Objetivo: este artigo apresenta a situação de deslocamento à qual foi encaminhado 0 povo emberá katío, devido à construção da hidrelétrica Urrá I (Alto Sinú-Córdoba), que priva a minoria de seu patrimônio territorial e cultural, e causa seu desaparecimento iminente como uma comunidade.

Metodologia: o documento expõe como a corrupção política e da justiça (através de seus pronunciamentos questionados) causou a "expulsão" do povo emberá katío de seus territórios ancestrais e sua realocação numa área urbana do município, onde não podiam realizar suas tarefas agrícolas, educativas, religiosas, de pesca e navegação, etc. Por consequência, o povo foi submetido a um processo de adaptabilidade ao novo sistema de vida até "desaparecer" como um grupo étnico.

Resultados: apesar da existência de legislação nacional e internacional que protege os direitos das comunidades indígenas e minorias, neste caso não houve aplicação efetiva da lei, de modo que, quando o Tribunal Constitucional interveio, enfrentou fatos que foram descumpridos.

Conclusão: 0 incumprimento dos mandatos da Constituição Nacional e dos tratados internacionais por parte das autoridades que administram a justiça causou uma situação de desalojamento, deslocamento e subsequente desaparecimento por aculturação da comunidade emberá katío do Alto Sinú.

Palavras-chave: direitos indígenas fundamentais, consulta prévia, corrupção política, indígenas emberá katío, denegação de justiça, barragem Urrá ।. 


\section{INTRODUCCIÓN}

Cuando se instituyó la Constitución Política de Colombia, el Gobierno planteó en su presentación que a partir de ese momento el Estado sería regido por unas nuevas y avanzadas normas jurídicas derivadas de la positivización del ordenamiento jurídico. Todos los habitantes tendrían el reconocimiento de su ciudadanía mediante el ejercicio de sus derechos fundamentales y además debían contribuir al desarrollo de la Constitución ${ }^{1}$ mediante la constante exigencia de su cumplimiento y aplicación. Esto se conseguiría con su participación política en condiciones de "justicia, igualdad, conocimiento, libertad y paz dentro de un marco jurídico, democrático y participativo", que así aseguraría un "orden político, económico y social justo", en el que los principios fundamentales garantizaban una sociedad "democrática, participativa y pluralista".

La construcción de la represa hidroeléctrica de Urrá I, contemporánea a la Constitución de 1991, es en un buen ejemplo de cuán distantes pueden estar en la realidad los principios jurídicos constitucionales con las prácticas sociales, económicas y jurídicas de los sectores políticos que detentan el poder regional y nacional. Sus objetivos están orientados a la satisfacción de sus intereses particulares en desmedro de los colectivos, sin importarles las consecuencias que sus actuaciones políticas tengan en las poblaciones más vulnerables, válidas de contar con el respaldo, y en su mayoría, por acción u omisión de los órganos de control y de justicia.

La construcción de la represa de Urrá I, inicialmente, se presentó cumpliendo la normatividad constitucional y legal que debía amparar a la comunidad indígena embera katío, directamente afectada por la construcción de la hidroeléctrica y por su posterior actividad generadora de energía. En este contexto, se reseñan los idearios de quienes planteaban que la Constitución de 1991 posibilitaba nuevos espacios de interacción democrática de las relaciones de poder con criterios de respeto, justicia y equidad con las minorías, y para el caso, las poblaciones indígenas.

Un aspecto relevante del presente trabajo se basa en la articulación de la consulta previa, en tanto compromiso del Estado colombiano con la normatividad internacional, con la implicación de hacer parte de su bloque constitucional, teniendo además la categoría

Véase Constitución Política de Colombia [Const]. Julio 7 de 1991 (Colombia). de derecho fundamental de obligatoria consideración y cumplimiento, la cual en su momento fue intencionalmente desconocido para posibilitar la construcción de la mencionada represa. Todo en función de satisfacer los intereses particulares, lesionando los de las minorías, en este caso la comunidad embera katío que fue desplazada y desarraigada de sus territorios ancestrales y de lo que ellos representaban en su cosmovisión cultural y espiritual, hasta el punto de exponerlos a mediano plazo a su desaparición étnica.

En este sentido, se articuló la aparente necesidad de construir la represa -justificada en el control de los recursos hídricos y la generación de energía para la región-con los intereses políticos regionales que impusieron la realización del proyecto, a pesar de no ser económica ni ambientalmente viable. Se obviaron los derechos de la comunidad indígena embera katío y después se les negó la justicia, en el ejercicio de sus justificadas y válidas oposiciones en defensa de su entorno territorial, ambiental y cultural, con su consiguiente despojo, consecuencia previsible de la asimetría de los ejercicios de poder, en clara y evidente negación de sus derechos fundamentales, hasta la tardía intervención de la Corte Constitucional para corregir un daño irreversible.

\section{La Constitución Política y los Derechos Fundamentales}

En la clausura de las sesiones de la Asamblea Constituyente, el entonces presidente de Colombia, César Gaviria, sintetizó lo que consideraba que era la nueva Constitución, que las distintas fuerzas políticas participantes habían elaborado y acordado. Así manifestó en su alocución: "Hemos luchado por construir una patria abierta a la participación, que no excluya a nadie, que les ofrezca a todos un lugar bajo el sol de Colombia, que cobije por igual a pobres y ricos, a fuertes y débiles, a los que han sido gestores de nuestra historia y a quienes serán los protagonistas del mañana"2.

Gaviria resaltó que cada ciudadano a partir de ahora tendría un poder real, en el que los criterios de justicia social se orientarían a:

Proteger a quienes requieran apoyo $[\ldots]$ por quienes merecen especial protección. Dicha preocupación por las minorías no refleja una actitud paternalista.

2 Id. Pág. XIX. 
Es el resultado de que todos estaremos aquí reunidos, por primera vez en nuestra historia, en una misma casa, frente a frente, en condiciones de igualdad [...] en la que los indígenas y los demás grupos étnicos minoritarios en verdad cuentan. ${ }^{3}$

Tras destacar las bondades políticas y sociales de la nueva Constitución, el presidente Gaviria recalcó que esta había tenido en cuenta la diversidad que constituía a la nación, dado que "en materia de derechos [era] amplia, participativa y democrática en cuanto a lo político, fuerte y sólida en lo que se refiere a la justicia, [...] revolucionaria en lo social"; en donde "millones de colombianos [estarán] dispuestos a exigir que se cumpla, que no se quede escrita, que sea un instrumento para transformar la realidad"; y a partir de "una nueva concepción de la democracia participativa [se ha generado] un nuevo orden político, más legítimo [...] menos desigual y más justo, abierto a la convivencia pacífica de todos los grupos que conforman una comunidad"4.

El presidente Gaviria continuó hablando sobre las bondades de la Constitución de 1991, señalando que:

En esta democracia participativa grupos de ciudadanos [...] podrán vetar aquellas decisiones que consideren altamente perjudiciales [...] podrán intervenir en foros, para que sus opiniones sean consideradas cuando se vayan a tomar decisiones que los afecten [...] en esta democracia participativa lo más importante es el poder de cada ciudadano [...] No más injusticias. No más privilegios. No más atropellos. Respetemos la dignidad de todos [...] bajo la Constitución no hay ningún espacio para la violencia política, como tampoco la hay para otras formas reprochables de autoritarismo, de intolerancia, de privilegio o de atropello. ${ }^{5}$

La Constitución Política de Colombia de 1991 en su Preámbulo estableció que se sancionaba y promulgaba: "Con el fin de fortalecer la unidad de la Nación y asegurar a sus integrantes la vida, la convivencia, el trabajo, la justicia, la igualdad [...] dentro de un marco jurídico, democrático y participativo que garantice un orden político, económico y social justo”.
En el Título I, se definieron los principios fundamentales que habrían de regirla, determinando que a partir de su vigencia "Colombia se constituía en un Estado social de derecho, democrática, participativa y pluralista, fundada en el respeto de la dignidad humana, en el trabajo y la solidaridad de las personas que la integran", en el que prevalecería el interés general.

A su vez, los fines esenciales del Estado eran "servir a la comunidad, promover la prosperidad general y garantizar la efectividad de los principios, derechos y deberes consagrados" para facilitar "la participación de todos en las decisiones que los afectan y en la vida económica, política, administrativa y cultural de la Nación”, y para asegurar "la convivencia pacífica y la vigencia de un orden justo”. Por tal razón: "Las autoridades estarán instituidas para proteger a todos los ciudadanos en sus derechos y libertades, y para asegurar el cumplimiento de los deberes sociales del Estado y de los particulares", definiendo también que: "La soberanía reside exclusivamente en el pueblo, del cual emana el poder público”, por lo cual le corresponde al pueblo ejercerla en forma directa o por medio de sus representantes"6.

\subsection{Las Comunidades Indígenas en la Constitución Colombiana}

De acuerdo con los principios fundamentales que rigen la Constitución Política, la legislación ampara y protege a las comunidades indígenas, lo cual se resalta en el artículo 7: "El Estado reconoce y protege la diversidad étnica y cultural de la nación colombiana", y en el artículo 8: "Es obligación del Estado $\mathrm{y}$ de las personas proteger las riquezas culturales y naturales de la nación"7.

Con los dos artículos anteriores el Estado reconoce y por tanto se compromete a proteger la diversidad étnica y cultural que representan, entre otros, las comunidades indígenas. Igual ocurre con las culturas que históricamente estas han creado y recreado, las cuales expresan sus costumbres, conductas, saberes y creencias ancestrales representados durante el ejercicio de su cotidianidad, que le otorgan sentido, identidad, pertenencia y cohesión a su colectividad.

El artículo 10, además de reconocer el castellano como el idioma oficial del país, determina que:

\footnotetext{
Id. Págs. XIX y xx.

Id. Págs. XIX y $\mathrm{xx}$.

Id. Págs. xxv y xxvi.
}

6 Id. Págs. 1 y 3
$7 \quad$ Id. Págs. 4 y 5 
"Las lenguas y dialectos de los grupos étnicos son también oficiales en sus territorios. La enseñanza que se imparta en las comunidades con tradiciones lingüísticas propias será bilingüe", siendo las lenguas $\mathrm{y}$ los dialectos expresiones fundamentales del acervo cultural.

El contexto de la educación a la que tienen derecho las comunidades indígenas como recurso para reproducir, transmitir y desarrollar su cultura quedó definido en el Capítulo 2, que trata de los derechos sociales y culturales ${ }^{8}$, dado que: "Los integrantes de los grupos étnicos tendrán derecho a una formación que respete y desarrolle su identidad cultural" (artículo 68), quedando claro que su sentido se orientará a respetar y a desarrollar su identidad cultural.

En cuanto a los derechos económicos, el artículo 63 estableció que "los parques naturales, las tierras comunales de grupos étnicos, las tierras de resguardo, el patrimonio arqueológico de la nación y los demás bienes que determine la ley son inalienables, imprescriptibles e inembargables". El artículo 72 establece que las comunidades étnicas e indígenas ubicadas en territorios donde hayan constituido algún tipo de riqueza arqueológica tienen derechos especiales sobre dichos patrimonios que constituyen de por sí su riqueza cultural, de esta manera:

El patrimonio cultural de la nación está bajo la protección del Estado. El patrimonio arqueológico y otros bienes culturales que conforman la identidad nacional, pertenecen a la nación y son inalienables, inembargables e imprescriptibles [...] la Ley reglamentará los derechos especiales que pudieran tener los grupos étnicos asentados en territorios de riqueza arqueológica. ${ }^{9}$

En el Capítulo 5, se hace referencia a las Jurisdicciones Especiales, y en el artículo 246 se estableció que las "autoridades de los pueblos indígenas podrán ejercer funciones jurisdiccionales dentro de su ámbito territorial, de conformidad con sus propias normas y procedimientos" en concordancia con la Constitución y las leyes de la República, "correspondiéndole a la ley establecer las relaciones y la manera de coordinar dichas jurisdicciones especiales con el sistema jurídico del país"10.

Id. Pág. 23.

Id. Págs. 21 y 24.

10 Id. Pág. 98.

\subsection{Las Comunidades Indígenas en el Marco de la Legislación Internacional}

El Estado colombiano, el 6 de marzo de 1991, suscribió el Convenio 169 sobre los Pueblos Indígenas y Tribales en los Pueblos de Países Independientes, que fue adoptado por la 76. ${ }^{a}$ reunión de la Conferencia General de la Organización Internacional del Trabajo (OIT) reunida en Ginebra en 1989, la cual desarrolló y ajustó a las nuevas realidades el Convenio y sus recomendaciones sobre las poblaciones indígenas y tribales de 1957, basados en:

[...] los términos de la Declaración Universal de los Derechos Humanos, del Pacto Internacional de Derechos Económicos, Sociales y Culturales de 1966, del Pacto Internacional de Derechos Civiles y Políticos de $1966^{11}$, y de los instrumentos internacionales sobre la prevención de la discriminación, entre estos la Declaración de las Naciones Unidas sobre la eliminación de todas las formas de discriminación racial de 1963 , y la Convención Internacional sobre la eliminación de todas las formas de discriminación racial de 1965 , y la Declaración sobre la raza y los prejuicios raciales de 1978.

En el artículo 2 del Convenio citado, se estableció la responsabilidad de los gobiernos de: "Desarrollar, con la participación de los pueblos interesados, una acción coordinada y sistemática con miras a proteger los derechos de esos pueblos y a garantizar el respeto de su integridad"12. Las medidas adoptadas para este fin debían permitirles la plena igualdad de derechos y oportunidades que la legislación nacional otorga al resto de la población, promoviendo efectivamente sus derechos sociales, económicos y culturales, respetando su identidad social y cultural, sus costumbres y tradiciones, y sus instituciones; así como ayudarlos a eliminar las diferencias socioeconómicas que existan entre los indígenas y la comunidad nacional, de una manera compatible con sus aspiraciones y formas de vida.

En el artículo 3, parágrafo 2, se estableció que: "No deberá emplearse ninguna forma de fuerza o de

11 Máximo Pacheco Gómez. Los Derechos Humanos. Documentos BÁsicos. Jurídica de Chile. (1987).

12 Organización Internacional del Trabajo (OIT). Convenio 169 de la oit sobre Pueblos Indígenas y Tribales en Países INDEPENDIENTES, en LXXVi Reunión de la Conferencia General de la oIT, Ginebra, 7 de junio de 1989. 
coerción que viole los derechos humanos y las libertades fundamentales de los pueblos interesados". Así mismo, en el artículo 4 se estableció que de acuerdo con los intereses de los pueblos indígenas, se deberán adoptar las medidas necesarias para "salvaguardar las personas, las instituciones, los bienes, el trabajo, las culturas y el medio ambiente de los pueblos interesados". En consideración al artículo 5, se "deberán reconocer, respetar y proteger sus valores y prácticas sociales, culturales, y costumbres religiosas y espirituales", teniendo en cuenta las problemáticas que se deriven de dichas actividades, facilitándoles los medios que les permitan adaptarse a nuevas condiciones de vida o laborales.

El artículo 6 del Convenio hace obligatorio para el Estado reconocer y tener en cuenta a las comunidades indígenas y sus representantes que llegaran a ser afectadas por decisiones de carácter legislativo y/o administrativo, otorgándoles las condiciones que les permitan participar libremente y en igualdad de condiciones con los demás sectores interesados, y garantizándoles que sus planteamientos y oposiciones respecto a las políticas y los programas que se pretendan instaurar y que les sean lesivos sean tenidos en cuenta por las entidades del Estado correspondientes ${ }^{13}$.

Para esto, se les deben facilitar las condiciones que posibiliten la creación y el desarrollo de las instituciones y las iniciativas de las comunidades indígenas, otorgándoles los recursos necesarios que requieran para alcanzar los fines propuestos. Desde la perspectiva jurídica y legal, se hace obligatorio que en los procesos de negociación prevalezca el principio fundamental de la buena fe, como garantía de que contarán con la debida protección institucional y la información para tomar sus decisiones, y de que el consentimiento dado no haya sido sometido a condicionamiento o limitación alguna.

El artículo 7 del Convenio obliga a reconocer la plena autonomía de las comunidades indígenas respecto a su visión del mundo y su futuro, que necesariamente estará relacionado con su cosmovisión, sus principios y sus valores ancestrales. Les corresponde a ellos determinar cuáles serán sus objetivos de desarrollo humano, social, económico y cultural, y la manera como serán integrados en sus formas de vivir y de relacionarse con sus sistemas institucionales particulares.

13 Id. Pág. 3.
Para garantizar el cabal cumplimiento de esta disposición, los pueblos indígenas tendrán el derecho a participar en "la formulación, aplicación y evaluación de los planes y programas de desarrollo nacional y regional" que en su consideración pudieran afectarlos. Se entiende que de acuerdo con el numeral 2, los proyectos de desarrollo de las regiones donde estén asentados los indígenas tendrán como objetivo promover su mejoramiento y bienestar. Los planes y programas de desarrollo regional deberán consultar sus intereses y necesidades, determinando "la incidencia social, espiritual y cultural y sobre el medio ambiente que las actividades de desarrollo previstas puedan tener sobre esos pueblos, debiendo proteger y preservar el medio ambiente de los territorios que habitan".

El Convenio en su artículo 8 definió que: "Al aplicar la legislación nacional a los pueblos interesados deberán tomarse debidamente en consideración sus costumbres o su derecho consuetudinario". En el contexto de justicias distintas y complementarias, Solano y Padilla advierten la necesidad de establecer los mecanismos que permitan una mayor y efectiva coordinación entre los dos tipos de justicia coexistentes: "Las tensiones entre estas dos formas de administrar justicia, la nacional y la tradicional, plantean nuevamente la necesidad de una ley de coordinación entre la rama judicial y las autoridades indígenas"14.

Lo anterior hace relevante, tal como advierte Flórez al referenciar la trascendencia jurídica del Derecho Mayor para las comunidades indígenas, considerar el contexto de las relaciones jurídicas entre los dos tipos de justicia: "El Derecho Mayor es un derecho directamente asociado con la tierra, con la herencia de los ancestros que poblaron ciertos territorios hace cientos de años. Por lo tanto, es importante describir esta noción teniendo en cuenta que se trata, en esencia, de un derecho al territorio"15.

El Derecho Mayor, reseña Flórez, en el contexto de la cosmogonía indígena, es reconocido por las comunidades como "un derecho heredado que no ha sido creado por los hombres sino por la divinidad". Está en correspondencia y se refleja "en los ritos de las comunidades, que buscan preservar la tierra y la

14 Véase Nancy Solano de Jinete y Germán Humberto Padilla Ospina. La colisión cultural entre dos visiones: justicia indígena y derecho estatal. Misión Jurídica Revista de Derecho y Ciencias Sociales 7. 2014.

15 Véase Carlos Albeiro Flórez-Vargas. El concepto de Derecho Mayor: una aproximación desde la cosmología andina. DIXI 24. Octubre 2016. Pág. 69. 
fertilidad de la comunidad. Sin embargo, el Estado colombiano -según el sentimiento de muchos miembros de la comunidad- no ha facilitado los procesos para que el Derecho Mayor sea reconocido, violentando de esta manera su forma de percibir el mundo y de existir o actuar en él"16. En consecuencia, la lucha histórica por el respeto a sus territorios, por lo que este representa en sus sistemas de valores, será el eje central de sus reivindicaciones ante la sociedad que se lo arrebata y el Estado que no cumple con sus compromisos constitucionales.

El artículo 12 del Convenio establece que los pueblos indígenas deberán contar con la plena y debida protección de sus derechos fundamentales, y pueden de manera individual o colectiva (sus organismos de representación) acudir ante las instancias jurídicas correspondientes para reclamar por el respeto y el cumplimiento de dichos derechos. El Estado debe garantizar el acceso a la debida justicia, asesorándolos para que estos comprendan y hagan un uso adecuado de los procesos legales correspondientes.

Históricamente, la comunidad embera katío en general ha tendido a intentar resolver sus posibles conflictos legales internamente, entre otras razones por la desconfianza que les genera la justicia ordinaria (externa) y por el desconocimiento que tienen de ella y los procedimientos que sigue.

$\mathrm{Al}$ analizar los aspectos relativos al conflicto cultural generado por la aplicación de las dos visiones de justicia que coexisten para las comunidades indígenas, Solano y Padilla señalan que los wayuú: "No acuden a la justicia ordinaria por desconocimiento y poca efectividad de la misma, por evitar la tramitología, porque no saben leer y escribir [...] [además] porque no creen en la justicia blanca, o simplemente desconfían de ella", y porque entienden que al acudir a la justicia externa "el conflicto suscitado puede, incluso, agravarse"17.

El Convenio, en la Parte in que hace referencia a los territorios ocupados ancestralmente por los indígenas, en el artículo 13, advierte que "el Estado deberá tener en cuenta y respetar el significado y la importancia especial que el hábitat, el territorio habitado y utilizado por las comunidades indígenas representan para ellas, desde la perspectiva de sus culturas y sus valores espirituales".

En concordancia con el artículo 13, el artículo 14 estipuló que se deberá reconocer a los pueblos

16 Id. Pág. 70.

17 Id. Pág. 322. indígenas su derecho de propiedad y de posesión sobre las tierras que ancestralmente ocupaban, y que se deberá salvaguardar su derecho a utilizar las tierras que aunque no estén ocupadas por ellos, las requieran para garantizar la realización de sus actividades tradicionales en función de su subsistencia. Al Gobierno le corresponde tomar las medidas necesarias que garanticen la protección real y efectiva de sus derechos de propiedad y posesión sobre sus tierras, instituyendo los procedimientos jurídicos necesarios para dar solución pronta y efectiva a las reivindicaciones que sobre sus tierras llegaran a plantear los pueblos indígenas.

El artículo 15 del Convenio define los derechos de los indígenas a disponer y proteger los recursos naturales existentes en sus territorios, por lo que les corresponde participar en su administración y utilización siendo partícipes de la toma de decisiones respecto a su utilización y conservación.

Cuando los recursos minerales del subsuelo sean de propiedad del Estado o cuando este tenga derecho sobre otros recursos existentes en el territorio indígena, le corresponderá al Gobierno establecer los procedimientos que permitan consultar a las comunidades indígenas sobre los posibles perjuicios que su explotación pueda causar y sobre el posible impacto de su intervención, "antes de emprender o autorizar cualquier programa de prospección o explotación de los recursos existentes en sus tierras". A las comunidades indígenas les corresponde participar de los beneficios que se generen de su explotación, y tienen derecho a ser indemnizados por cualquier perjuicio que pudieran sufrir como consecuencia. La importancia del artículo 15 radica en que establece y define los criterios de la debida y obligatoria consulta previa a los pueblos indígenas.

El Convenio 169 de 1989, con el propósito de evitar el desplazamiento de los indígenas, determinó que solo excepcionalmente se permitirá su traslado y reubicación, y que en caso de ser necesario este procedimiento, solo podrá realizarse con su pleno y libre consentimiento, teniendo los pueblos indígenas el total conocimiento de las razones y causas que lo requieren.

En el caso de que la comunidad se oponga a ser trasladada de su territorio, su reubicación solo podrá darse teniendo en cuenta estrictamente la legislación nacional y agotando los procedimientos adecuados. Es necesario que los pueblos indígenas estén debidamente representados e informados de las consecuencias de dichas decisiones, y se les debe garantizar el 
derecho de poder retornar a sus territorios ancestrales "cuando dejen de existir las causas que motivaron su traslado y reubicación".

Si las circunstancias impiden su retorno a los territorios que ocupan, se deberá garantizar que los indígenas reciban en compensación "tierras cuya calidad y cuyo estatuto jurídico sean por lo menos iguales a los de las tierras que ocupaban anteriormente, y que les permitan subvenir a sus necesidades y garantizar su desarrollo futuro". Cuando la comunidad opte por recibir contraprestaciones en dinero o especie, estas deberán ser apropiadas y cubrir plenamente cualquier daño o perjuicio generado por su desplazamiento.

El artículo 17 del Convenio determina que se deben respetar las modalidades existentes de transmisión de los derechos sobre la tierra entre los miembros de los pueblos indígenas. Es obligatorio consultarlos sobre su interés y capacidad de enajenar sus tierras o transferir sus derechos sobre ellas por fuera de su comunidad. Los indígenas deberán contar con una protección especial que impida que foráneos se aprovechen de su desconocimiento de la ley, ocasionándoles perjuicios sobre el uso, posesión o propiedad de sus tierras, a fin de evitar que puedan ser despojados de sus tierras por extraños a sus comunidades, con la consiguiente explotación de las tierras ${ }^{18}$.

El Gobierno colombiano, mediante la Ley 21 de 1991, ratificó el Convenio 169 de la ort sobre Pueblos Indígenas y Tribales en Países Independientes, que pasó a ser parte del bloque de constitucionalidad, siendo obligatorio el cumplimiento de lo establecido en dicho Convenio.

Uno de los aspectos positivos de la ratificación del Convenio 169, y su carácter vinculante, fue el de instituir y convertir la consulta previa en un derecho fundamental para los pueblos indígenas, a fin de utilizarla o invocarla como mecanismo de concertación y decisión colectiva comunitaria, estableciendo y definiendo jurídicamente las responsabilidades que le competen a los Estados en cuanto al "reconocimiento [y protección], tradiciones, legislación, costumbres y tradiciones respecto a la tenencia de la tierra."

\subsection{La Consulta Previa}

Uno de los aspectos jurídicos relevantes del Convenio es la instauración de la obligatoriedad de la consulta previa a la que debe someterse cualquier situación

18 OIT, supra, nota 12 que pudiera afectar los derechos de las comunidades indígenas o que les concerniera. Esto fue reafirmado por la Oficina del Alto Comisionado de las Naciones Unidas para los Derechos Humanos (OACNUDH), que al respecto se pronunció manifestando que: "La consulta contribuye a la protección de los derechos de los pueblos indígenas cuando entran en riesgo frente a las demandas y los requerimientos de sociedades numéricamente mayoritarias, y con mayor poder de decisión en las esferas de lo público y de lo privado"19.

En varias ocasiones, la Corte Constitucional se ha manifestado respecto al artículo 6 del Convenio 169, sobre el derecho a la consulta, que implica: "Consultar a los pueblos interesados, mediante procedimientos apropiados y en particular a través de sus instituciones representativas, cada vez que se prevean medidas legislativas o administrativas susceptibles de afectarles directamente". Es así como confirmó que: "El derecho fundamental de la comunidad a preservar la integridad se garantiza y efectiviza a través de otro derecho que también tiene el carácter de fundamental, como es el derecho de participación de la comunidad" 20 .

La OACNUDH, con respecto a las obligaciones del Estado adquiridas por el Convenio 169, "exige que los gobiernos lleven a cabo acciones coordinadas y sistemáticas con el fin de proteger los derechos de los pueblos indígenas y garantizar el respeto de su integridad", estableciendo la obligación de "consultar a los pueblos interesados, mediante procedimientos apropiados y en particular a través de sus instituciones representativas, cada vez que se prevean medidas legislativas o administrativas susceptibles de afectarles directamente"21.

La OACNUDH recalca que "las consultas llevadas a cabo en aplicación de este convenio deberán efectuarse [...] con la finalidad de llegar a un acuerdo o lograr el consentimiento acerca de las medidas propuestas". Y en este contexto se señala que en la Sentencia C-891 de 2002 la Corte Constitucional expresó que la consulta: "Constituye un instrumento básico para preservar la integridad étnica, social,

19 Véase Oficina del Alto Comisionado por los Derechos Humanos. El DERECHO DE LOS PUEBlos INDÍGENAS A LA CONSUlTA PREVIA, LIBRE E INFORMADA. Nuevas Ediciones. (2012). Pág. 16.

20 Véase Corte Constitucional de Colombia. Sentencia SU039/97 (M.P.: Antonio Barrera Carbonell; febrero 3 de 1997).

21 Oficina del Alto Comisionado por los Derechos Humanos, supra, nota 19, Pág. 30. 
económica y cultural de las comunidades indígenas, y para asegurar por ende, su subsistencia como grupo social"22.

Desde la perspectiva de las comunidades indígenas, el derecho que las rige es ancestral y está basado en el Derecho Mayor o Ley de Origen, y en consecuencia, esto debe ser el referente en la toma de decisiones legislativas que se llegaran a tomar al respecto: "Cuando hablamos de derecho de los pueblos indígenas, tenemos que comenzar por lo primero y propio; nuestra Ley de Origen, nuestro Derecho Mayor o Derecho Propio que nos asiste y otorga identidad, son nuestras leyes, formas de gobierno y justicia propia"23.

La existencia y vigencia de un derecho propio de los indígenas implica el autorreconocimiento y la autoafirmación de un sistema legal normativo específico y particular, de origen y desarrollo ancestral, que les permite ser sujetos jurídicos de su propia Constitución, que si bien se expresa en sus costumbres y creencias, no se reduce a estas, sino que refleja la existencia y persistencia de un derecho indígena específico, vigente en sus procedimientos y códigos normativos que regulan sus relaciones sociales y jurídicas internas.

El derecho propio es la valoración, el reconocimiento y la aceptación de la existencia de un derecho indígena, vigente en sus procedimientos y prácticas jurídicas aplicadas en su interior; y basado en una normatividad ajustada a su realidad y a sus necesidades de regular sus relaciones, a partir de su valoración cultural y visión del mundo aplicado al deber ser de cómo gobernar las relaciones entre sus miembros y el sentido de su existencia como comunidad.

La reivindicación indígena de una Constitución propia que prioriza el ejercicio de su derecho ancestral, y teniendo en cuenta que es una minoría respecto a la Constitución de la nación donde ha quedado incorporado su territorio como consecuencia de relaciones históricas de dominación, implica necesariamente la existencia de dos sistemas jurídicos, que bien pueden ser opuestos si no hay un reconocimiento explícito de su existencia o pueden ser complementarios si este se da, y mediante el cual le corresponderá a la comunidad indígena interactuar y relacionarse, asumiendo en su sabiduría que extraterritorialmente

22 Véase Corte Constitucional de Colombia. Sentencia C-891/02 (M.P.: Jaime Araujo Rentería; mayo 13 de 2002).

23 Oficina del Alto Comisionado por los Derechos Humanos, supra, nota 19, Pág. 30. está sometida a un sistema jurídico distinto en los términos de la concepción y la aplicación de la justicia.

Ambas sociedades deberán reconocer, a partir de aceptar que forman parte de un todo étnico y cultural múltiple y diverso, la validez de la coexistencia de modelos plurales jurídicos en un mismo territorio-nación que satisfacen sus necesidades jurídicas. Esto implica, a su vez, que dichas sociedades pluriculturales sean regidas por consenso por modelos igualmente pluriculturales válidos en el interior de sus territorios, cumpliendo funciones jurídicas específicas de acuerdo con sus valores culturales más relevantes, y en los que cualquier interpretación jurídica solo será válida y pertinente si se aprecia en el contexto particular en donde se ejerce.

En relación con lo expuesto por Luis Evelis Andrade, de la Organización Nacional Indígena de Colombia (ONIC), en el artículo 8 del Convenio 169 reconocido por la Ley 21 de 1991, la legislación vigente debía tener en cuenta sus costumbres y su derecho consuetudinario, permitiéndoles conservar sus propias instituciones, en concordancia con los derechos fundamentales y los derechos humanos ${ }^{24}$.

La OACNUDH, al definir las bases de la consulta previa, libre e informada, recalca que esta debe sustentarse en el principio de la buena fe, como en su momento lo estableció la Corte Constitucional en su Sentencia SU-383 de 2003, y como lo recopila la ONIC: "Las consultas [...] en aplicación de este Convenio deberán efectuarse de buena fe y de una manera apropiada a las circunstancias con la finalidad de llegar a un acuerdo o lograr el consentimiento de la comunidad indígena, basados en los lineamientos del Convenio 169 de la orT”25, y brindándoles la información pertinente de tal modo que conozcan a cabalidad el impacto que tendrán los programas en su hábitat y en sus estructuras cognitivas y espirituales.

En el caso de que se requiera el traslado de las comunidades indígenas de sus territorios ancestrales, el consentimiento debe ser adquirido de tal manera que: la comunidad indígena afectada cuente con el debido conocimiento del proyecto que se realizará, la manera como se ejecutará, el posible impacto socioeconómico, cultural y político respecto a su futuro como comunidad; $y$ también debe

24 Véase Organización Nacional Indígena de Colombia (ONIC). COMPILACIÓN Y SELECCIÓN DE LOS FALLOS Y DECISIONES JUDICIALES DE LA JURISDiCCIÓn EsPecial Indígena 1980-2006. Consejo Superior de la Judicatura. (2006). Pág. 23.

25 Id. 
ser escuchada en sus objeciones y pretensiones en defensa de su intereses y en este contexto, pronunciarse sobre su viabilidad.

Se deberá estimular su participación activa y efectiva en la toma de las decisiones requeridas y que sean concertadas, siendo claro que la comunidad indígena deberá contar con las garantías que permitan que actúe libremente, y sin interferencias extrañas, en la evaluación de los proyectos sometidos a su consideración, y que sus posiciones sean tenidas en cuenta por las autoridades competentes como parte de la concertación que se deberá alcanzar, tal como lo estableció la Corte Constitucional en su Sentencia C-891/02 ${ }^{26}$.

\section{LA COMUNIDAD INDÍGENA} EMBERA Katío

Actualmente, en Colombia viven cerca de 600.000 indígenas, organizados en 81 grupos distribuidos en una cuarta parte del territorio nacional, los cuales aportan una riqueza cultural de 75 lenguas diferentes, según lo reseña la $\operatorname{CIDH}^{27}$ (2008). La comunidad indígena embera katío hace parte de los pueblos embera, constituidos también por los embera chamí y los eperara siapidara, quienes tienen un origen común en los indígenas chocó, que inicialmente compartieron una misma lengua (poco diferenciada fonéticamente) y la cosmovisión jaibaná. Los chocó afrontaron la conquista y la colonización española que influyeron en sus formas de organización social y cultural. La evangelización y la acción de los colonos sobre su territorio determinaron su segmentación espacial y el despojo de sus tierras.

El censo del DANE en el 2005 determinó la existencia de 38.259 indígenas embera katío, con 50,7\% de hombres y $49,3 \%$ de mujeres (18.876 personas). Los indígenas embera katío están distribuidos así: en Antioquia, donde habita el 33,5\% de la población (12.815 personas); en el Chocó, con el 26,5\% (10.148 personas); y en Córdoba, con el 13,4\% (5.132 personas); el $26,6 \%$ reside en otros lugares y el $13,6 \%$ reside en zonas urbanas. La comunidad katío constituye el

\footnotetext{
26 Corte Constitucional de Colombia, supra, nota 22.

27 Véase Comisión Interamericana de Derechos Humanos (CIDH). Informe SObre la Situación de los Derechos HuMANOS EN COLOMBIA. CIDH. (1994).
}

2,7\% de la población indígena colombiana; el 67,2\% de los embera katío hablan el lenguaje katío. El $41,8 \%$ de la población indígena es analfabeta, mientras que el 40,8\% tenía algún tipo de escolaridad. Es crítico que el 13,8\% de los embera katío manifestó haber estado en condiciones de ayuno, al no poder ingerir alimentos durante algunos días de la semana anterior al censo ${ }^{28}$.

El Ministerio de Cultura señala que la cosmogonía embera implica que estos le otorguen una valoración social y religiosa al territorio en el que interactúan con la naturaleza; y consideran que existen espacios de reserva vedados a la realización de actividades económicas (caza, pesca, recolección, siembra, desmonte, aserrío de madera), dado que allí residen sus creadores. Es así como "los cementerios, ríos, montañas, lagos, lagunas, quebradas, sitios de origen, manglares encantados" son lugares a los que solo se puede acceder contando con el debido permiso de sus espíritus, previas ceremonias y rituales de purificación, limpieza, y armonización ${ }^{29}$.

En el documento del Ministerio de Cultura, se reconoce que los embera katío de Córdoba tienen una economía de subsistencia basada en la pesca, la caza y la recolección, aunque paulatinamente han ido asumiendo una agricultura estacionaria que les reporta maíz, plátano y demás productos de pancojer. La organización social de los embera katío se sustenta en la familia nuclear, en la que el parentesco se establece por línea materna y paterna y la autoridad la ejerce el padre.

La imagen del jaibaná contribuye a la integración social y a la armonía en el interior de la comunidad y su representación se transmite por generaciones. A partir de la Ley 89 de 1890, la figura líder del abuelo fue desplazada organizándose en cabildos, que tienen su estructura organizativa y participativa primero en sus localidades y sus asesores; la comunidad constituye el cabildo mayor, que ejerce la representación política $^{30}$.

28 Véase Departamento Administrativo Nacional de Estadística (Dane). Censo Nacional 2005. Colombia Estadística. Series Estadísticas. DANE. (2007)

29 Véase Ministerio de Cultura. Embera Katío. Serie 200 AÑos 1810-2010. Cultura es Independencia. Ministerio de Cultura. (2010).

30 Id. 


\section{La Represa y Central Hidroeléctrica de Urrá I}

De acuerdo con la Corporación Autónoma Regional de los Valles del Sinú y del San Jorge (cvs), en el Valle del Sinú eran frecuentes las inundaciones que afectaban a los pobladores y agricultores de la región; esto llevó a plantear la necesidad de regularizar el río para favorecer el desarrollo agroindustrial. Según Viloria de la Hoz, las propuestas iniciales que datan de 1940 planteaban represarlo en su parte alta (subregión del Alto Sinú), ubicada entre los municipios de Tierra Alta y Valencia, con una superficie de $5.690 \mathrm{~km}^{2}$ que contienen el Parque Nacional Natural de Paramillo, lugar donde nacen los ríos Sinú y San Jorge; "los terrenos altos de la región son de baja fertilidad, propios para el pastoreo y cultivos de subsistencia", en tanto que en la parte baja son fértiles, "aptos para toda clase de cultivos, pastos y plantaciones forestales, con algunas limitaciones"31.

El proyecto de construir una represa en la región data de 1940, según Viloria de la $\mathrm{Hoz}^{32}$, y entre 1950 y 1980 se cambiaron los criterios de intervención. El proyecto dejó de regularizar el río para generar energía mediante una hidroeléctrica, y a mediados de los años noventa se decidió construir dicha represa, regulando a su vez los caudales del río Sinúu ${ }^{33}$. Madero advierte que en 1952 se había propuesto la construcción de la represa de Urrá, controlando las inundaciones y aumentando de 20.000 a 150.000 hectáreas los terrenos cultivables. Esto permitió el control de las aguas durante el invierno y garantizó la irrigación de la tierra durante el verano, posibilitando el desarrollo agroindustrial de la región. En este contexto, la producción de energía tenía un carácter marginal ${ }^{34}$.

Según Madero, fue la crisis energética mundial de los años 1973 y 1974 lo que hizo que de nuevo se volviera a contemplar la construcción de la hidroeléctrica. La Corporación Hidroeléctrica de la Costa Atlántica (Corelca) inició los estudios de factibilidad, en tanto que la cvs proyectaba un modelo de desarrollo multipropósito, de desarrollo agrícola y

31 Véase Joaquín Viloria de la Hoz. Estructura eCONómicA DE Cereté, MUNicipio AGRÍCOLA DE CÓRDOBA. ECONOMÍAS lOCALES en el Caribe colombiano. Siete estudios de caso. Banco de la República. (2005). Pág. 282.

32 Id.

33 Id. Pág. 283.

34 Véase Evelio Luis Madero Arteaga. Deshaciendo EI ENCANTO. IMPACTOS DE LA REPRESA URRÁ I SOBRE TRES COMUNidAdes de la Ciénaga Grande de Lorica. Tesis de maestría, Universidad de los Andes, Bogotá, Colombia. (2014). energético. En 1975, el Banco Mundial otorgó los empréstitos para construir en la región el Proyecto de Drenaje y Riego Córdoba II. En 1977, Corelca fue informada de la factibilidad de construir las hidroeléctricas Urrá I (que generaría 340 mw) y Urrá II (que generaría $740 \mathrm{mw})^{35}$. Esto implicó que el proyecto agropecuario, en términos de la utilización de las aguas y la adecuación de tierras, dependiera de las necesidades y proyecciones energéticas.

Como lo señala Madero, en 1978, de acuerdo con el Plan de Desarrollo de la región financiado por el Banco Interamericano de Desarrollo (BID), se definieron los beneficios e impactos negativos que tendría sobre la región la construcción de las hidroeléctricas Urrá I y Urrá II, advirtiendo sobre la concentración de la tierra, dado que "el 1,5\% de los terratenientes eran dueños del 50\% de las tierras bajas (las más fértiles)"36. El Estudio Nacional de Energía de 1982 recomendó tener en cuenta el impacto ambiental de las obras, así como considerar que los costos por kw/h de la hidroeléctrica de Urrá eran mayores que los de los demás proyectos.

A pesar de las anteriores consideraciones, en 1983 se anunció la apertura de la licitación para las obras civiles de Urrá i; los daños ecológicos generados por la inundación de 60.200 hectáreas de bosque tropical húmedo, la calidad del agua para el consumo humano y los sobrecostos que implicaría la producción de energía pusieron en evidencia que detrás de la construcción de la represa Urrá I lo que primaban eran intereses regionales y políticos ${ }^{37}$. En 1985, se empezaron a descubrir irregularidades en la contratación y sobrecostos de las obras, en lo cual estaban implicados familiares de políticos de la región; y junto con esto, los previsibles daños ecológicos que no se habían contemplado durante la ejecución de las obras, paralelo al desplazamiento de las poblaciones campesinas e indígenas de la región. A pesar de los serios cuestionamientos que se le estaban haciendo al proyecto hidroeléctrico Urrá I, los políticos de la Costa optaron por defender a cualquier costo la realización de la obra ${ }^{38}$.

En 1991, aunque estaba en vigencia la nueva Constitución que garantizaba los derechos de las poblaciones indígenas, de manera irregular los políticos de la Costa continuaron presionando a las entidades encargadas de dar el visto bueno al inicio

\footnotetext{
35 Id. Pág. 23.

36 Id. Págs. 25 y 26.

37 Id.

38 Id. Pág. 28.
} 
y desarrollo de las obras, entre ellas las entidades ambientales. Así, se obvió cumplir con las disposiciones derivadas del Convenio 169 de 1989 de la orT, que hacían obligatoria la consulta previa que para entonces había adquirido el carácter de derecho fundamental y además hacía parte del bloque de constitucionalidad, de acuerdo con los artículos 93 y 94 de la Constitución Nacional.

Durango señala las irregularidades que se dieron durante la construcción de la represa Urrá I, entre ellas los sobrecostos: el costo fue de 780 millones de dólares y genera 340 megavatios, en tanto que la Hidroeléctrica de San Carlos, en Antioquia, costó 300 millones de dólares y genera 350 megavatios. El daño ecológico se tradujo en la inundación de 7.000 hectáreas de bosques, 400 de estas pertenecientes al Parque Nacional Natural de Paramillo, con lo que se afectaron los medios de vida y la existencia de los embera katío y de la comunidad de pescadores del área ${ }^{39}$.

Los manejos corruptos de la clase política costeña fueron puestos en evidencia por el dirigente político Sergio Fajardo en julio del 2008 en el artículo de El Espectador "El rezago de la Costa Caribe", en el que señaló:

[...] las razones que explican el atraso y la pobreza de la región Caribe, visibles en la poca educación de la población y su desinterés por participar políticamente se debe a que lo público se convirtió en el botín de los políticos, con algunas excepciones, apropiándose de los recursos del Estado en beneficio personal. Para esto han creado empresas electorales sustentadas en el clientelismo que reparten migajas a cambio de votos; para poder saquear los recursos públicos.

Los mismos políticos que se asociaron con los paramilitares para consolidarse en el poder regional; de este modo han elevado el clientelismo y la corrupción a su máximo nivel, siendo hábiles negociadores con el poder central para extorsionarlo políticamente, sacrificando los intereses de los pobres para optimizar las ganancias de sus empresas electorales, bloqueando el desarrollo de la región de la Costa ${ }^{40}$.

39 Véase Gerardo Durango Álvarez. Derechos fundamentales de los pueblos indígenas. El caso del pueblo Embera Katío y la represa de Urrá: un análisis desde la Corte Constitucional colombiana. Revista Opinión JuRídica 14. 2008. Págs. 33-52.

40 Véase Sergio Fajardo. El rezago de la Costa Caribe. El Espectador. 19 de julio de 2008. Disponible en http://www.elespectador.com/impreso/nacional/articuloimpreso-el-rezago-de-costa -caribe

\section{LA NEGACIÓN DE JUSTICIA \\ A LOS INDÍGENAS EMBERA KaTío DEL Alto Sinú}

En su análisis del pronunciamiento de la Corte Constitucional, Durango señala las normas jurídicas que fueron desconocidas durante la construcción de la represa de Urrá, tales como el derecho a ser consultado antes de inundar su territorio, con lo que se violaron el artículo 330 de la Constitución Nacional, la Ley 21 de 1991, el Decreto 1320 del 13 de julio de 1998 y la Ley 685 del 15 de agosto de $2001^{41}$. En este contexto, se desconoció su derecho a preservar su integridad territorial y el dominio sobre el resguardo, relacionados con su derecho fundamental a la supervivencia, a la explotación de los recursos naturales y a la debida protección de su identidad e integridad étnica, cultural, social y económica, además del "derecho a la igualdad en la prestación del servicio público de atención a la salud".

Durango señala que un antecedente que prueba la negación al derecho a la debida justicia es la tutela instaurada por los embera katío ante el Tribunal Superior del Distrito Judicial de Montería (Sala Laboral), que la declaró improcedente en lo pertinente a la violación al derecho a la consulta previa anterior a la inundación. Este Tribunal consideró "las garantías provistas por el Ministerio del Medio Ambiente, manifestando que los requisitos de la licencia ambiental salvaguardan con amplitud los derechos de las comunidades indígenas" ${ }^{\text {"42 }}$.

En la segunda instancia elevada ante la Corte Suprema de Justicia (Sala de Casación Laboral), se descalificó la presunta mala fe por parte de la empresa Urrá s.A. Por su parte, el Tribunal Superior del Distrito Judicial de Santafé de Bogotá (Sala Penal) declaró improcedente la tutela presentada por la comunidad, buscando que se le ampararan "unos derechos colectivos" como "la participación de los pueblos indígenas, la autonomía y el derecho al territorio", dado que dicha protección debía alcanzarse mediante una acción popular. Así mismo, determinó que no existía un perjuicio irremediable que se pudiera evitar con la tutela, pues carecía de las pretensiones de objeto. En contravía a los anteriores pronunciamientos, la Corte Constitucional señaló que con el procedimiento irregular que había permitido la construcción de la

41 Durango Álvarez, supra, nota 39, Págs. 40 y 41.

42 Id. Pág. 43. 
represa de Urrá I, se habían violado los derechos fundamentales del pueblo embera katío, en la medida en que se desconoció y se omitió la consulta previa que de manera formal y real debía haberse realizado con la comunidad indígena.

Como lo indica Durango, la Corte Constitucional reconoció que a los embera katío les violaron los derechos a la participación, al debido proceso, a la integridad étnica y al respeto al carácter multicultural de la nación colombiana, afectando gravemente su derecho a la subsistencia. El Estado incumplió los compromisos adquiridos internacionalmente e integrados al derecho interno mediante la Ley 21 de 1991 respecto a la protección de los derechos humanos de los pueblos indígenas ${ }^{43}$. La Corte Constitucional, mediante la Sentencia T-652 de 1998, revocó las sentencias del Tribunal Superior del Distrito Judicial de Córdoba y de la Corte Suprema, tutelando los derechos fundamentales a la supervivencia, a la integridad étnica, cultural, social y económica, a la participación y al debido proceso del pueblo embera katío.

Es claro que los cuestionables pronunciamientos del Tribunal Superior del Distrito Judicial de Montería y de la Corte Suprema permitieron y le dieron las condiciones y los tiempos necesarios a la empresa Urrá I para que adelantara sus obras civiles, de tal modo que finalmente cuando la Corte Constitucional se pronunció en derecho, tuvo que hacerlo ante un hecho cumplido.

La Corte Constitucional, en su Sentencia T-652 de 1998, al pronunciarse respecto al derecho a la consulta previa, sostuvo que llevarla a cabo "cuando se toman decisiones que afectan a los pueblos indígenas es una forma de promover su desarrollo y multiculturalidad". Con un carácter remedial, procedió a ordenar al Instituto Colombiano de la Reforma Agraria (Incora) y al Ministerio del Interior a que procedieran, en ejercicio de sus funciones, a realizar las actuaciones "tendientes a unificar el resguardo del pueblo embera-katío del Alto Sinú”. Así mismo, ordenó a la Empresa Multipropósito Urrá s.A. a indemnizar a los embera katío del Alto Sinú, en una cuantía tal que garantizara su supervivencia mientras procedía a asumir los cambios culturales, sociales y económicos, consecuencia de la vulneración de los derechos en la que habían incurrido tanto el Estado como la empresa Urrá $\mathrm{I}^{44}$.

\footnotetext{
43 Id. Pág. 45.

44 Véase Corte Constitucional de Colombia. Sentencia T-652/98 (M.P.: Carlos Gaviria Díaz; noviembre 10 de 1998).
}

El pronunciamiento de la Corte Constitucional, si bien pareciera que favoreció a la comunidad embera katío, realmente terminó legalizando las actuaciones irregulares de la dirigencia costeña, sobre las que no se pronunció, y las de la empresa Urrá I, tal como se puede apreciar en la actualidad. Pese al mandato de la ley, a los embera katío no se les otorgó un territorio específico para constituir su resguardo, que les permitiera reunir de nuevo a su comunidad; en consecuencia, se los expuso al desplazamiento forzado y a convivir con los demás sectores de la población. Se vieron expuestos a un paulatino proceso de mestizaje que además de llevarlos a perder su integridad étnica, cultural y social, los sometió a ser sujetos de presiones y expoliación por parte de los paramilitares de la región, quienes coexistiendo y compartiendo el poder local, se han dedicado a la expropiación y acumulación de la tierra en complicidad con el narcotráfico.

Con el desarraigo de su hábitat histórico, los miembros de la comunidad embera katío tuvieron que cambiar sus hábitos alimenticios derivados de la pesca y la agricultura que les garantizaba su sostenimiento alimentario; esto fue la consecuencia de la inundación de cerca de 7.400 hectáreas de tierra que requirió la construcción de la represa a pesar de que servían de sustento agrícola, pesquero y habitacional para los indígenas.

El desplazamiento forzado al que fue sometida la comunidad indígena embera katío del Alto Sinú implicó que perdieran sus tierras más productivas; además, se les fracturó su estructura social y comunitaria. Una clara demostración de que en la apropiación de las tierras de la comunidad para la construcción de la represa de Urrá I hubo intereses diferentes a los de dotar a la región de una estructura energética es que esta no se requería y fue construida con sobrecostos. Lo que permite tipificar la corrupción de los líderes regionales de la Costa es el asesinato selectivo de los dirigentes de la comunidad embera katío, entre ellos Lucindo Domicó y Kimy Pernía Domicó. Este último fue asesinado y desaparecido por los paramilitares, que se opusieron desde una perspectiva legal al proyecto, sin que hasta el momento las instituciones y organismos competentes de la justicia colombiana hayan avanzado en sus investigaciones de identificación y sanción a los responsables intelectuales y materiales de tales crímenes contra personas protegidas.

Las indemnizaciones que ordenó la Corte Constitucional en la Sentencia T-652 de 1998 como una compensación monetaria para la comunidad, mientras se adaptaban a un nuevo entorno espacial, 
contribuyeron a romper su estructura comunitaria, puesto que así se estimuló el individualismo. Los miembros de la comunidad embera katío asumieron el uso de dichos recursos como una manera de sobrevivir aisladamente, fracturando su estructura y tejido social al copiar los patrones propios de la sociedad de consumo en la cual fueron insertados. Desde una visión étnica y antropológica, abandonaron sus usos y costumbres, y esto los llevó a la paulatina pérdida de su identidad comunitaria.

Los miembros de la comunidad embera katío fueron insertados en sus nuevos entornos culturales, sociales y económicos, de los que su identidad societaria había tratado de mantenerlos alejados como una forma de mantener su sistema cultural de principios y valores autóctonos. En estos ambientes territoriales y culturales alternos, fueron discriminados y marginados por su condición de indígenas y fueron sometidos a relaciones de dominación y explotación económica. Los indígenas no tenían otro recurso que su fuerza de trabajo no especializada y por tanto expuesta a bajas remuneraciones o a la negación de la vinculación laboral misma, y esto los sumió en condiciones de pobreza absoluta, en las cuales se mantienen actualmente, y que los expone a su desaparición en un corto plazo generacional.

Todas las cuestionables actuaciones de los tribunales competentes ponen en evidencia que las minorías siempre estarán expuestas a tener que afrontar las asimetrías derivadas del ejercicio de los poderes emergentes que coexisten y se han imbricado y apropiado de la justicia. En consecuencia, la administración de la justicia y la existencia y vigencia de la Constitución Política, cuando no logran ser llevados hasta las más altas instancias jurídicas para su revisión, no pasan de ser un saludo a la bandera, con los costos humanos, sociales, culturales y económicos que de esto derivan, afectando gravemente a la democracia que dicen representar y garantizar.

\section{Conclusiones}

La promulgación y la institucionalización de una nueva Constitución en 1991 advertía en su Preámbulo $\mathrm{y}$ en sus principios fundamentales que se fortalecería la unión de la nación, puesto que el Estado sería regido por unas nuevas y avanzadas normas jurídicas derivadas de la positivización del ordenamiento jurídico, lo cual permitiría que todos fueran reconocidos como ciudadanos (entre ellos los indígenas), con el pleno disfrute de sus derechos fundamentales, y que su activa participación política contribuiría al fortalecimiento de la democracia al exigir su cumplimiento y aplicación en un marco democrático, participativo y pluralista de "justicia, igualdad, conocimiento, libertad y paz". Este hecho les permitió creer a los pueblos indígenas que podrían contar con una legislación que, además de reconocer su existencia, avalaría su inclusión social y política entre los criterios de diversidad, pluralidad, democracia y respeto a la dignidad humana, explícitos en el artículo 7 de reconocer y proteger la diversidad étnica y cultural de la nación, y demás artículos que hacían referencia en su legislación menor a los pueblos indígenas. Y que en consecuencia, el Estado, por fin y por mandato constitucional, los empoderaría y contribuiría a su consolidación cultural y social, garantizándoles las condiciones básicas de desarrollo social y humano que requirieran para su existencia.

Lo anterior estaba respaldado por la vinculación del Estado colombiano al Convenio 169 sobre los Pueblos Indígenas y Tribales en los Pueblos de Países Independientes, el cual había sido adoptado por la 76. ${ }^{a}$ reunión de la Conferencia General de la OIT realizada en Ginebra en 1989, y por las demás obligaciones jurídicas internacionales vigentes. Los pueblos indígenas contaban con la normatividad legal que no solo reconocía su existencia, sino que además los empoderaba legalmente a nivel nacional e internacional para posibilitar que los derechos enunciados fueran reales en su aplicación y disfrute. En este caso, para los indígenas colombianos significaba lograr por fin un reconocimiento jurídico a sus derechos históricamente negados y desconocidos desde la conquista misma.

El Convenio 169 haría obligatoria la consulta previa sobre cualquier aspecto que pudiera afectar sus derechos, y además de reconocerlos como sujetos de derechos, les devolvió la capacidad de asumir su derecho a ser tenidos en cuenta en los aspectos que consideraran relevantes y a negociar en derecho aquellos aspectos que pudieran afectarlos o que fueran de su interés frente a las posibles demandas externas (mayoritarias) y con un mayor poder de decisión. En diversas ocasiones, por su parte, la Corte Constitucional se manifestó respaldando el derecho indígena a la consulta previa, dado que mediante su participación, la comunidad garantizaría su 
permanencia e integridad, siendo esto un reconocimiento pleno de la vigencia ancestral de un Derecho Mayor o Derecho Propio.

Sin embargo, la construcción de la represa de Urrá I mostró la fragilidad de las instituciones del país respecto a su capacidad e interés de aplicar la legislación vigente. De hecho, el proceso seguido por la clase política de la Costa Caribe colombiana para llevar a cabo la construcción de una represa que además de no ser necesaria fue doblemente costosa con respecto a otras similares, es ejemplo de cómo los dirigentes de la región han acumulado vía elecciones un poder político que ejercen en función de sus intereses personales, poniendo el Estado al servicio de sus prácticas corruptas, en procura de un enriquecimiento inmediato y desmedido a costa de los recursos públicos y de la población afectada.

La clase política impuso sus reglas de juego para lograr la construcción de la represa Urrá I y ante los tribunales la presentó como un hecho cumplido, al que solo cabía hacer reparaciones tardías. Intencionalmente y con la complicidad de la justicia regional, sobre la cual tiene una gran influencia, desconoció la observancia del debido proceso que cobijaba a los embera katío, en procura de garantizar mínimamente sus derechos. Del mismo modo, fieles a sus prácticas de que los fines justifican los medios, no dudaron en hacer ejercicio de las formas más extremas de violencia. Es así como al desplazamiento de la población indígena se sumaron el asesinato y el amedrentamiento de los representantes indígenas que se opusieron a sus cuestionados proyectos.

Cuando finalmente la Corte Constitucional se pronunció al respecto, reconociendo las múltiples y constantes violaciones a los derechos humanos a los que habían sido sometidos los embera katío, su pronunciamiento no dejó de ser un saludo a la bandera realizado desde una visión institucional. En este sentido, las tardías reparaciones ordenadas solo contribuyeron a que la comunidad embera katío viera confirmada su desconfianza hacia la justicia menor imperante, mientras forzados al desplazamiento, desde entonces, se han visto expuestos a llevar y a afrontar una vida marginal que inexorablemente los expone a su desaparición étnica, mientras conviven en los cinturones de miseria de los municipios cercanos a lo que alguna vez fuera su hábitat, un espacio en el que era posible mantener una identidad propia y conservar los valores y creencias derivados de sus cosmogonías ancestrales.

\section{REFERENCIAS}

Adolfo Meisel Roca. Las economías departamentales del Caribe continental colombiano. Banco de la República. (2007).

Carlos Albeiro Flórez-Vargas. El concepto de Derecho Mayor: una aproximación desde la cosmología andina. DIXI 24. Octubre 2016.

Comisión Interamericana de Derechos Humanos (СIDH). INFORME SOBRE LA SITUACIÓN DE LOS DERECHOS Humanos en Colombia. CidH. (1994). Disponible en http://www.hchr.org.co/documentoseinformes/documentos/html/informes/osi/cidh/CIDH\%202o\%20 Informe\%20Colombia\%20capitulo\%2011.html

Constitución Política de Colombia [Const]. Julio 7 de 1991 (Colombia).

Corte Constitucional de Colombia. Convenio C-169/89 Convenio sobre Pueblos Indígenas y Tribales en Países Independientes. Junio 27 de 1989.

Corte Constitucional de Colombia. Sentencia T-380/93 (M.P.: Eduardo Cifuentes Muñoz).

Corte Constitucional de Colombia. Sentencia T-652/98 (M.P.: Carlos Gaviria Díaz; noviembre 10 de 1998).

Corte Constitucional de Colombia. Sentencia SU-039/97 (м.P.: Antonio Barrera Carbonell; febrero 3 de 1997).

Corte Constitucional de Colombia. Sentencia C-891/02 (M.P.: Jaime Araujo Rentería; mayo 13 de 2002).

Corte Constitucional de Colombia. Sentencia SU-383/02 (M.P.: Álvaro Tafur Galvis; enero 27 de 2003).

Departamento Administrativo Nacional de Estadística (Dane). Censo Nacional 2005. Colombia Estadística. Series Estadísticas. Dane. (2007)

Evelio Luis Madero Arteaga. Deshaciendo el encanto. IMPACTOS DE LA REPRESA URRÁ I SOBRE TRES COMUnidades de la Ciénaga Grande de Lorica. Tesis de maestría, Universidad de los Andes, Bogotá, Colombia. (2014).

Gerardo Durango Álvarez. Derechos fundamentales de los pueblos indígenas. El caso del pueblo Embera Katío y la represa de Urrá: un análisis desde la Corte Constitucional colombiana. Revista Opinión JuRídica 14. 2008. Págs. 33-52.

Joaquín Viloria de la Hoz. Estructura económica de Cereté, municipio agrícola de Córdoba. Economías locales en el Caribe colombiano. Siete estudios De CASO. Banco de la República. (2005) 
Ministerio de Cultura. Embera Katío. Serie 200 AÑos 1810-2010. Cultura es Independencia. Ministerio de Cultura. (2010).

Máximo Pacheco Gómez. Los Derechos humanos. DocuMENTos BÁsicos. Jurídica de Chile. (1987).

Nancy Solano de Jinete y Germán Humberto Padilla Ospina. La colisión cultural entre dos visiones: justicia indígena $y$ derecho estatal. Misión JurídicA Revista DE DereCHO Y CiENCIAS SOCIALES 7. 2014.

Ley 21 de 1991. Por la cual se aprueba el Convenio número 169 sobre Pueblos Indígenas y Tribales en Países Independientes, adoptado por la 76a. reunión de la Conferencia General de la O.I.T., Ginebra 1989. Do N. ${ }^{\circ}$ 39720. Marzo 6 de 1991.

Oficina del Alto Comisionado por los Derechos Humanos. EL DERECHO DE LOS PUEBLOS INDÍGENAS A LA CONSULTA PREVIA, LIBRE E INFORMADA. Nuevas Ediciones. (2012).
Organización Nacional Indígena de Colombia (ONIC). CoMPILACIÓN Y SELECCIÓN DE LOS FALLOS Y DECISIONES JUdiCIALES DE LA JURISDICCIÓN ESPECIAL INDÍGENA 1980-2006. Consejo Superior de la Judicatura. (2006).

Organización Internacional del Trabajo (oIT). Convenio 169 DE LA OIT SOBRe Pueblos Indígenas y Tribales en Países Independientes, en Lxxvi Reunión de la Conferencia General de la oIT, Ginebra, 7 de junio de 1989.

Sergio Fajardo. El Rezago de la Costa CARIBE. El Espectador. 19 de julio de 2008. Disponible en http://www. elespectador.com/impreso/nacional/articuloimpreso-el-rezago-de-costa-caribe 